\title{
Chapter 2 \\ Cultures of Knowledge Use in Policymaking: The Functions of Research in German and UK Immigration Policy
}

\author{
Christina Boswell
}

\subsection{Introduction}

Despite the extensive literature on patterns of knowledge utilisation in policymaking, there is very little scholarship comparing different 'cultures' of knowledge use across polities. By 'culture', I am referring to the historically specific and cumulatively learned patterns of values and beliefs that orient social action (Eckstein 1997: 226). The literature on national policy styles suggests that such values and beliefs can shape patterns of policymaking in different systems of public administration. ${ }^{1}$ But it is likely that such differences in administrative cultures also produce distinct ways of thinking about and drawing on expert knowledge. This chapter aims to explore how such differences might influence patterns of research use in immigration policy in Germany and the UK. ${ }^{2}$

\footnotetext{
${ }^{1}$ There have also been a number of contributions applying cultural theory to understand particular ways of framing public policy problems (Hoppe 2002; Geva-May 2002), information bias in organisations (Thompson and Wildavsky 1986), or constructions of risk (Douglas 1982). These approaches draw on Mary Douglas' famous group/grid typology, explaining variation in terms of quite abstractly defined dispositions which influence actions (Douglas 1982; Douglas and Wildavsky 1982). If we want a more historically specific account of cultural variation, we require a richer empirical account of national policy styles.

${ }^{2}$ Of course, there are a number of other variables not associated with culture that might shape patterns of knowledge use. These include features of the policy area or political debate, or the nature of the organisation responsible for policymaking (as I discuss elsewhere - see Boswell 2008 , 2009). However, in this chapter I would like to focus on the notion that different national or organisational cultures might influence how knowledge is used.

C. Boswell (ه)

Politics and International Relations, School of Social and Political Sciences,

University of Edinburgh, Edinburgh, UK

e-mail: Christina.Boswell@ed.ac.uk
} 
Before we proceed, I would like to suggest a slightly unconventional way of thinking about knowledge utilisation. Most theories of the use of research in policymaking adopt more or less explicitly 'instrumentalist' theories. On these accounts, policymakers draw on research as a resource for informing adjustments to policy. Thus knowledge is valued instrumentally, in the sense that it is mobilised as a means of improving policy. Such theories neglect a number of other important functions that knowledge can play in policymaking. In recent work (Boswell 2009) I have argued for the need to recognise that research frequently plays a symbolic, rather than instrumental, role in policymaking. In many cases, knowledge is not valued so much for its contribution to adjusting policy interventions, but rather for its potential to demonstrate the capacity of policymakers to make informed decisions, or to provide evidence to underpin their preferences. Thus in additional to its instrumental function, research can play a role in legitimising actors involved in policymaking; and/or lending authority to their policy choices. We can therefore distinguish between three possible functions of expert knowledge in political debate and policymaking:

The first of these is an instrumental function. This refers to the use of knowledge to adjust substantive policy, or outputs. Also known as 'problem-solving' knowledge, this is the type of research use most typically referred to in academic and practitioner discussions about knowledge utilisation. The assumption is that policymakers are keen to draw on knowledge to improve the content of policy, in order to realise political and/or organisational goals.

The second possible function of knowledge use is what can be termed a legitimising function. By being seen to draw on expert knowledge, an organisation can enhance its legitimacy and bolster its claim to resources or jurisdiction over particular policy areas. In this sense knowledge can endow organisations with 'epistemic authority' (Herbst 2003: 484).

The third function of knowledge is a substantiating function. Expert knowledge can lend authority to particular policy positions, helping to substantiate organisational preferences in cases of political contestation. As with legitimising knowledge, this type of knowledge use is essentially symbolic: knowledge is drawn on to signal authority or legitimacy, rather than to adjust output. However, whereas legitimising knowledge is about underpinning the authority of policymakers or organisations, substantiating knowledge is mobilised to support specific arguments. As we shall see, this implies a rather different pattern of commissioning, absorbing and marshalling expert knowledge in political debate.

This three-way typology allows us to develop a more nuanced understanding of different patterns of knowledge use. It provides scope for understanding not just the extent to which policymakers appear to be interested in using knowledge, but also the different functions such knowledge might serve in political debate and policymaking. As we shall see, this distinction is crucial in making sense of the notion that there are distinct 'cultures' of knowledge use in different national administrations. As I shall argue, one can indeed identify distinct national cultures in the sense that different administrations appear to attach varying levels of importance to research or expertise in the abstract. However, such general attitudes towards 
research are not necessarily good predictors of how far research is drawn on to shape policy (the instrumental function), or to underpin preferences in political debate (the substantiating function). Indeed, factors other than 'national cultures' - in particular the character of political debate and the nature of the policy sector - appear to have more influence on the actual take-up of expert knowledge.

The chapter draws on the three-way typology of the functions of knowledge to make sense of cultures of knowledge use in two organisations dealing with immigration and asylum policy: the German Federal Office for Migration and Refugees (BAMF - Bundesamt fuer Migration und Fluechtlinge); and the UK Home Office, especially its Borders and Immigration Agencu (previously the Immigration and Nationality Directorate, and now renamed the UK Border Agency). In Sect. 2.2, I provide a brief sketch of the two organisations, setting up a number of expectations about cultures of knowledge use. In Sects. 2.3 and 2.4, I explore whether these expectations are met through analysing patterns of knowledge use over the period 2000-2004.

\subsection{Cultures of Knowledge Use in the BAMF and the Home Office}

Comparative studies of bureaucratic cultures in liberal democracies typically divide these into two types. First is the Anglo-Saxon, entrepreneurial style, in which decision-making is characterised by informal and personalised forms of bargaining and negotiation. The second is the continental rationalist style, in which decisions are based on formal, universalised rules, and organisational roles are more stratified (Peters 1995: 48-9). Within this typology, the UK tends to be depicted as the paradigmatic case of an entrepreneurial bureaucracy, making decisions on a pragmatic, case-by-case basis (Peters 1995: 50). Senior officials are valued for their managerial skills, rather than their technical knowledge. Germany, by contrast, is frequently portrayed as the archetypal rationalist bureaucracy. The state administration tends to derive legitimacy from conformity to formal laws and rational procedures (Jann 2003: 95; Beetham 1996: 52; Koenig 2000: 48). Bureaucrats gain credibility from their Fachkompetenz (professional competence), which usually denotes specialised technical skills (Lodge and Hood 2003: 136) notably law, but also increasingly economics.

These different bureaucratic styles have also been associated by some authors with different attitudes towards science. Willem Halffman, for example, argues that according to the British approach, the credibility of science does not hinge on standardised criteria for science, but rather on 'the quality and reasonableness of the experts who provide the scientific evaluations' (Halffman 2005: 461). Scientific credibility is attested by experts known to and trusted by the government, who are co-opted into informal decision-making circles (Jasanoff 1995). This can be contrasted to countries with more depersonalised ways of ascribing authority, and 
sharper boundaries between policy and science. In Germany, for example, scientific research is more strictly delineated from other forms of expertise, distinguishing itself through its formal standards of proof and evidence (Hellström 2000). As a result, scientific research has tended to be far more sequestered, with disputes among experts rarely becoming the object of public debate. Instead, such debate remains within the realm of acknowledged experts, who are accorded considerable deference for their knowledge. The only viable strategy for non-scientists to gain influence is to re-couch such debates in terms of rival values (Jasanoff 1995: 327), thereby justifying the interventions of non-specialists marshalling arguments based on values and interests, rather than expert knowledge.

Assuming this analysis is correct, we might expect it to produce quite different patterns of knowledge use in UK and German bureaucracies dealing with immigration and asylum. Indeed, one might even talk about different 'national models' of knowledge utilisation. Most notably, we would expect German officials to attach far more weight to research, not just as a means of adjusting output or substantiating decisions, but also in order to legitimise policymakers. In fact, given the more general points about rationalism in German bureaucracy, we might expect research to play an important role in lending authority both to administrative organisations (legitimising function) and to specific decisions (substantiating function). By contrast, we would expect UK officials to display less reverence for research in general, but make use of expertise on a more ad hoc, informal basis. Depending on the policy context, it might be marshalled to adjust output (instrumental function), but it would be less likely to play a major role in justifying decisions (substantiating function) or lending authority to organisations (legitimising function).

In what follows, I shall examine how far these expectations about different cultures of knowledge use are met. I shall do so by looking at the use of research in UK and German administrative agencies dealing with immigration policy. This enables us to examine patterns of knowledge use in different national contexts dealing with the same policy issues. In both cases, the analysis focuses on the period 2000-2004, a period in which both governments were building up in-house research units to provide expertise on migration. In this way we can compare two similar structures for producing and applying research in policymaking, within two ministries dealing with broadly similar policy remits. This allows us to hold constant variations in organisational approaches to knowledge use that might be specific to different policy sectors. Moreover, both Germany and the UK were going through similar phases in the reform of their immigration policies, attempting to introduce more liberal policies on skilled labour migration. Thus we might expect patterns of knowledge use in both cases to be influenced by similar political pressures, notably the need to justify more liberal labour migration policies. In short, many of the factors influencing knowledge utilisation in the two cases are likely to be similar, implying that any variation in knowledge use may well be attributable to cultural factors.

For each of the cases, I shall look at the structure and mandate of the research unit, the content of the research produced, its take-up by policymakers, as well as 
patterns of disseminating research. The latter is of especial interest in ascertaining how far research was valued for its legitimising function, rather than as a means of adjusting output. The research is based on a combination of semi-structured interviews and content analysis of organisational websites, policy documents and research outputs produced by the respective research units.

\subsection{The Federal Office for Migration and Refugees (BAMF)}

The BAMF started life in 1953 as the Federal Office for Foreign Refugees, an implementing agency of the Federal Interior Ministry. Initially responsible for processing asylum applications, it was given new powers by an Immigration Law which came into force at the beginning of 2005. The law made the agency responsible for developing and implementing new integration courses for immigrants coming to Germany. It also established a research capacity on migration, which was to evolve into the BAMF Research Group. In preparation for the changes, from 2003 onwards the agency carried out major restructuring to equip it to take on these new tasks, and by the end of 2005 the number of staff had risen again to 2,231.

The Research Group was based in one of the organisation's five departments, Department Two, which was responsible for external relations, information and communication. Recruitment of research staff began in late 2004, shortly before the group's official launch in January 2005. In line with Article 75 of the Immigration Law, the official goal of the Research Group is the 'production of analytical evidence for migration management'. As the group's website states:

The Immigration Law has increased the significance for policymaking of a number of core questions about migration. In order to underpin rational policy, we need to draw on a wide range of methodological and empirical approaches to address these questions. The particular responsibility of the Federal Office in this respect flows from its national and Europe wide status as a competence centre. To this end, it provides the legal, institutional and economic bases for compiling reports and analyses, reviews the results of its own and external migration and integration research, and thereby contributes to the conditions for efficient migration and integration policies. (BAMF website, 14.03.06)

The group's output was to comprise a mixture of internal research, and externally commissioned projects. Not surprisingly for a German agency, the research mandate is defined in a very legalistic way. As one senior researcher rather formally described it:

Paragraph 74 Number 4 states that the Federal Office... should have the task of developing and expanding the analytical basis for managing migration, and states in brackets that this should be 'supporting research' (Begleitforschung). And this means that it should review measures taken under the Immigration Law, to see how efficient it is in managing migration in the labour market and economic interests of Germany. That's what we focus our research on... These are the questions which we pose, to fulfil the mandate given us by the legislature. To expand and deepen the basis for the management of migration. (BAMF interview, February 2008) 
However, this rather broad-brush legalistic definition of the goals of research left open what sorts of projects the group should carry out. And indeed, when the group commenced its activities in late 2004 and early 2005 there was some uncertainty about its remit and research priorities. One of the earliest recruits notes:

I remember that at that time it was an open process. These people were brought together, then they appointed a head of unit ..., and then we had to sort out what we should actually do. There was the legal mandate to develop analytical evidence about the management of immigration, but not much more. And it was completely open how we should carry out this task. (Interview, Feb 2008)

Others described how the Research Group's activities and role evolved in a rather ad hoc fashion, as it took over projects from other ministries and from the European Migration Network.

Certain actors had a rather clearer picture of the group's role from the outset. The President of the BAMF, Dr. Schmid, was keen to send out a clear signal about BAMF's expertise, defining the Research Group as a 'competence centre' that would enhance the expertise of his organisation. As one official put it, Schmid 'is a politician, he didn't grow up in the administration. He saw clearly the strategic possibilities of research. Therefore he fought hard to have research here' (BAMF interview, Feb 2008). From the point of view of the BAMF leadership, as one official explained, the Centre brought credibility to the organisation. 'From our side, it's about competence. A better reputation, and possibilities for expansion' (Interview, February 2008).

But there was also a more pragmatic consideration, linked to attracting and retaining staff. Almost all of the researchers in the BAMF Research Group appeared to be aware of this, describing their sense of being 'estranged' from the rest of the agency, like a 'foreign body', even a 'separate universe'. Or as one person expressed it, 'My outfit isn't right, I don't wear a tie ... In my opinion we don't fit in here. Research needs autonomy ... It should be free from bureaucracy' (Interview, Feb 2008). This goes hand-in-hand with a sense that the organisation does not understand or appreciate their work.

Some of those from management had the view for a long time that these researchers come here from the university and don't do any work. And some felt that we were just doing what we wanted, for independent research and not for policy. We needed quite some time for them to understand that we work hard, and that we are not producing wild theories that have nothing to do with the office. (Interview, February 2008)

This is linked to the traditional reverence for legal training in the German civil service. One researcher explained how this meant that social scientists had very limited career prospects in the organisation. 'I don't think you can really make a career here in BAMF ... It's difficult, because everything's arranged around lawyers here' (Interview, Feb 2008).

Despite the concern on the part of senior BAMF officials to ensure the Research Group had sufficient academic credibility and autonomy, there was also concern among many of its researchers that their work would not be viewed as serious academic research outside of the organization. A number of younger or mid-career 
researchers were conscious of having to make a decision between returning to the academic system, or being 'co-opted' into a bureaucratic career with the consequent diminution of academic credibility.

The Research Group's first projects were selected in a rather haphazard fashion. Two relatively large projects were imported from the outside, not so much as part of a reflected strategy on the functions of BAMF, but because the new Research Group in BAMF seemed the obvious place to carry them out. One of these was the collation of panel data on new immigrants, which had been run as a pilot study and was now handed over to BAMF by the Interior Ministry. The second was a survey of selected immigrant groups in Germany, which until then had been a joint venture of the Interior Ministry and the Employment Ministry, but was now handed over to BAMF. A third project on migrants in the health sector had been commissioned by the European Migration Network, within which the BAMF served as contact point for Germany.

The BAMF also become responsible for drafting the annual Migration Report, which it considered to be a key part of its activities. As one member of the Research Group put it, 'We've managed to promote ourselves very well in one area, and that's the Migration Report. This is the report where you find very reliable and authoritative data on migration. It's a report that's used by so many people. My wish is that we could achieve a similar thing with other projects' (Interview, February 2008). Not surprisingly, the Research Group has been planning to launch a parallel Integration Report, though this is meeting some resistance from the Commissioner for Migration.

Other topics for research were proposed by the staff, reflecting their particular interests and experience. A number of projects were also commissioned from external researchers, especially in this initial phase. In general, as one researcher puts it, the research agenda 'wasn't really defined ... We had maybe one or two themes that we were required to work on, but otherwise we came up with the themes ourselves' (Interview, February 2008). As another researcher recalls, they defined themes that seemed to be politically topical, and that suited their own expertise. At that stage, the exercise was largely internal to the Research Group: 'I don't remember any strong influence from the BMI' [the Federal Interior Ministry] (BAMF interview, Feb 2008).

The seemingly ad hoc development of the Research Group's agenda suggests little reflection on the possible instrumental or substantiating role of such a research group, at least in this initial phase. Rather, the general impression is that the establishment of the Research Group reflected the BAMF's own interest in having a 'competence centre' to bolster its authority in this area. The Interior Ministry appeared to have no particular interest in making use of the Research Group, but was broadly supportive of its development and recognised the legal necessity of setting it up, given the provision for such a research unit in the Immigration Law.

However, over the course of 2005, officials in the Interior Ministry began to demonstrate increasing interest in drawing on the research group. As BAMF officials noted, the Ministry seemed to 'realise that there was competence here... Then there was almost an avalanche of requests, so that the ongoing projects had 
to be put to one side' (Interview, February 2008). One of the first requests was for an evaluation of the impact of a law on providing accommodation for Aussiedler, ethnic Germans from Central and East Europe who had relocated to Germany. The government's policy of dispersing these immigrants to different regions of the country had been challenged on constitutional grounds, as an infringement of individual rights, and the Interior Ministry was keen to commission research that would inform its response to this challenge. This appears to be a good example of the substantiating use of knowledge, with the government keen to elicit arguments that could feed into its response. However, reactions to the study produced by the Research Group also offer a good example of some of the initial communication problems arising between researchers and other officials. The Research Group had spent one-and-a-half years on the project, compiling data from surveys of Aussiedler and local authorities, which they presented in a 200-page report. ${ }^{3}$ The report was well-received, but it was also clear that a much shorter study would have sufficed. Moreover, the study did not provide any direct answer to the Ministry's underlying question, namely the impact of dispersal on the social integration of migrants. As one researcher points out, 'these were complex relationships', which could not easily be answered through social scientific research.

This gap in expectations between officials and researchers appears to have reflected a more general problem about how each side understood research. One BAMF researcher noted that many of the issues they dealt with required quite indepth study. 'But most don't want to go into too much depth, as they just need it for a specific purpose, a meeting or a political objective' (Interview, February 2008). As another researcher put it, at the beginning:

We needed to find a common language. The top management in the administration are mainly lawyers and suddenly there was this Research Group with social scientists. And the social scientists had a rather different understanding of what a study was... Sometimes a lawyer says he wants a study, and actually a 10-page report will suffice. We had to learn this ... I think we really came to terms with this in the first year. (BAMF interview, Feb 2008)

There have been a number of other studies commissioned by the Interior Ministry, mainly to provide data and analyses on topical areas of policy, such as the Muslim community in Germany, illegal immigrants in Germany, or levels of criminality amongst immigrants. The Interior Ministry appears to take an interest in these projects, and there is some communication during their development. However, the Ministry's interest tends to revolve around the scale and timeframe for research, rather than questions of research design or methodology. As with the Migration Report, one can infer that much of the demand for knowledge is about developing a descriptive overview of different immigrant groups: their location, characteristics and behaviour. The Interior Ministry is keen to elicit knowledge of its target

\footnotetext{
${ }^{3}$ Sonja Haug and Lenore Sauer, Abschlussbericht: Zuwanderung und Integration von (Spät) Aussiedlern - Ermittlung und Bewertung der Auswirkungen des Wohnortzuweisungsgesetzes (Research Report Nr. 3, Nuremberg, November 2007).
} 
populations, and to demonstrate that it has access to this sort of knowledge, and it has realised that the Research Group can be of use in this regard.

In conclusion, the sorts of projects being carried out by the Research Group appear to have shifted since early 2005. In the early stages, members of the Research Group seemed to exercise considerable autonomy in choosing research themes, and many of the projects were quite broad in scope. However, in the course of 2005 and 2006, other parts of the BAMF and the Interior Ministry began to commission studies and briefings. After an initial lack of interest in the Research Group's work, these officials appeared to be beginning to recognise the potential usefulness of the group's expertise. A major part of this has involved routine work preparing briefings and answers to parliamentary questions, arguably tasks for which the Research Group was not intended. Such contributions tend to take the form of legitimising or substantiating knowledge, produced to back up the authority of the Interior Ministry in speeches or briefings. The Interior Ministry has also commissioned some studies providing general data and analyses of key immigrant groups, using the group to provide background information on its target populations. This type of knowledge utilisation is likely to serve a variety of purposes for the Ministry, providing a general resource for enhancing the authority of its claims and, in some cases, guiding adjustments to output. For its part, the BAMF has made some limited use of the group to assist in its evaluations of integration courses, implying an instrumental function of knowledge.

On the whole, though, the Research Group's main benefit to the BAMF appears to have been in terms of its legitimising role. The Interior Ministry and other departments within the BAMF have numerous possible sources for gathering knowledge to inform or substantiate their programmes. Indeed, the integration department within the BAMF prefers to make use of far more specialised and applied expertise in guiding its policies. Instead, the main asset of this in-house research unit almost certainly resides in its legitimising function.

The importance of the legitimising function of research is underlined if we consider BAMF's attitude towards the dissemination of its research. The senior management of the BAMF were quite keen for the Group to have a high profile, and be present in the national media. For them, the main target is the policy community, as well as the wider public:

\footnotetext{
My basic assumption is that they want this (dissemination) because that's tied up with being a competence centre. And we have agreed with the president that we need to take pains to inform the wider public. That our impact increases, that we are invited to conferences. And we'll only achieve recognition if we disseminate our results.

[Author] To whom?

Mainly to the policy community that's dealing with these themes. (Interview, February 2008)
}

Or as another researcher put it, 'If the Federal Agency wants to be taken seriously as a competence centre, people must be able to present their research results and open them to discussion' (Interview, February 2008). This view is shared by the middle-management coordinating the Research Group. 
We've set ourselves the goal of becoming a centre of competence. And we're building that competence in different ways, and also insofar as we do good work, and discuss it... We want to be competent, we want our work to be in demand, we want to present ourselves as a specialist agency for migration and integration and that is an important task, which we've taken on board and which we are achieving. (Interview, Feb 2008)

As one researcher noted, 'Our president stated at the beginning that he wanted us to feature on page three of the FAZ (Frankfurter Allgemeine Zeitung). As far as I'm aware, we haven't managed that yet' (Interview, February 2008).

Thus senior officials within the organisation appear to be in favour of targeting the policy community, to ensure key actors working in the area are aware of the work of the Research Group. This implies an interest in demonstrating the BAMF's competence and expertise in this knowledge, and indicates that knowledge is seen as a source of legitimation.

In sum, despite some limited cases of research being drawn on to adjust output (instrumental function) or underpin policy preferences (substantiating function), the predominant value ascribed to expert knowledge appears to be as a means of shoring up the reputation and credibility of the BAMF (legitimising function). This legitimising function was the key rationale for setting up the unit in the first instance. And, although once in place certain parts of the organisation were able to identify other uses for the unit, the legitimising function has remained the most significant function of the unit over time.

The legitimising role of the Research Group becomes clear if we consider the outcome of the wrangle over how independent the unit should be within BAMF. The question was: should it remain a largely independent unit, thereby retaining research credibility and carrying out a legitimising function for the organisation? Or should it become a more responsive unit, carrying out tasks commissioned by other parts of the organisation, thus being more directly 'useful' as a provider of instrumental or substantiating research? The outcome was to opt for a more independent structure, confirming the importance of the unit's legitimising role within the BAMF - despite the fact that the research group was seen as largely irrelevant to many within the organisation. So one can say that its legitimising role was bought at the expense of performing an effective instrumental or substantiating function.

This conclusion may appear somewhat counter-intuitive, given the general points made earlier in the chapter about the importance attached to expertise in German bureaucratic culture. We shall return to this point after reviewing the UK case.

\subsection{The Home Office}

Immigration has fallen under the jurisdiction of the Home Office since 1793. After World War II, it was given responsibility not just for immigration control and asylum, but also the increasingly important area of 'race relations' (a British term describing what in other countries would be categorised as inter-ethnic relations or 
integration policy). ${ }^{4}$ Both sets of issues were dealt with by the Immigration and Nationality Directorate (IND), by far the largest part of the Home Office, with a staff of around 16,000 employers, accounting for over three quarters of the Home Office's staff..$^{5}$ In 2006 many aspects of race relations were transferred to the new Department for Communities and Local Government, which assumed responsibility for issues of diversity, anti-discrimination, integration and social cohesion, though IND retained responsibility for the integration of refugees. In Spring 2007, the IND was split off into a separate executive agency, the Border and Immigration Agency (BIA), though the agency remained part of the Home Office, and its functions are largely unchanged.

Immigration Research and Statistics Service (IRSS) was established in 2000 within the Home Office's Research, Development and Statistics (RDS) Directorate of the Home Office, with explicitly instrumental objectives. Its research goals were to support the delivery of asylum and immigration policies and programmes, develop knowledge about asylum and immigration, and develop methods for research with asylum seekers and other migrants. ${ }^{6}$ This interest in research appears to have been part of a more general move towards broadening the evidence base of policy. With the establishment of the new IRSS, twelve new research posts were created, covering four thematic areas: asylum, immigration, integration, and research on the new National Asylum Support Service (NASS) (Interview, June 2007). So there was clearly an interest in research across the board, not just in the area of labour migration. Tellingly, the recruitment drive was not limited to immigration and asylum, but was part of a general shift in the Home Office towards embracing evidence-based policy. It involved the recruitment of over 100 specialists across all sections - crime statistics, prisons, policing, and immigration. As one RDS researcher puts it,

The political message was: there should be evidence based policy, and in order to do that you need to bring in people who can do more sophisticated statistical analysis, but also people who can do research, and research management, so in-house research capacity ... And that was the function... To deliver on a series of, at that point ill-defined, research objectives. (Interview, June 2007)

In other words, it represented a drive to improve the evidence base of policy in general, more than an attempt to fill recognised knowledge gaps in particular policy areas.

The mandate of IRSS was initially couched in a rather broad way, as an attempt to define and fill gaps in knowledge, in order to underpin policymaking. It tallied well with the Blair government's modernising agenda and the notion of evidence-based

\footnotetext{
${ }^{4}$ See Chap. 13 on 'Research-Policy Dialogues in the UK' for further details.

${ }^{5}$ It is worth noting that most operational aspects of Home Office work are dealt with by organisations outside of the Home Office - the prison services (which alone employs around 47,000 staff), police, and so on. Immigration and asylum operations are somewhat unusual in being located within the department itself.

${ }^{6}$ See www.homeoffice.gov.uk/rds/immigration.htlm, accessed 6 December 2006.
} 
policymaking. And in line with this rather broad objective, the new researchers were given a degree of leverage in setting their own research priorities. However, many within IND were sceptical or even hostile towards the new cadre of researchers. IND were financing $50 \%$ of IRSS and its activities (the other half came from RDS' budget), contributing to a sense of ownership of the research agenda and output. Yet many were frustrated at the perceived irrelevance of the research being produced. One former official working on policy at the time noted that:

A lot of the time I would get the impression: what are they doing over there? There's a lot of people working there, and what are they producing? It was difficult to really access a structured kind of representation of what they were doing on a week to week basis, what was coming up, that sort of thing. (Interview, September 2006)

Insofar as officials were involved in research, this was certainly not with any great enthusiasm:

The research itself was not particularly prioritised by a lot of people, and meetings where we had to discuss research people would see as a bit of a chore. So what are we going to do? OK, we'll say what's on our mind at the moment, we won't get anything for a year, and then the whole agenda will have changed, it will just be a complete waste of time. (Interview, September 2006)

A former researcher describes the predicament from the perspective of IRSS researchers:

The Head of RDS was basically saying, you need to be identifying and developing evidence to fill gaps in order to inform policy. IND, however, tended to think, "we need evidence on $\mathrm{x}$, $y$ or z' - which were not necessarily broad areas of knowledge that needed to be filled, but areas where they had particular policy objectives driven by the flavour of the day. (Interview, June 2007)

This meant that 'as far as IND was concerned, at that time we were a thorn in their side... I think there was a sense at that point that they'd created something of a monster' (Interview, June 2007).

By around 2002-2003 there was growing dissatisfaction within IND about the role and output of IRSS, and in particular over the perceived lack of fit between IRSS research and the IND's policy imperatives (Interviews, May and June 2007). In the words of one commentator, IRS was seen as 'detached from political reality'; a former Home Office official described the perception as one that the IRS 'had gone off on a frolic of our own' (Interview, June 2007). Some of the criticism was directed at research which did not corroborate IND sources. In other cases, research was seen as being too abstract, and not relevant to the delivery of IND targets. So the complaint was that it was not sufficiently instrumental. There seemed to be little acknowledgement of the value of research as a means of legitimation for the organisation.

The various criticisms of IRSS' role and priorities culminated in a restructuring exercise in 2004, with the IRSS being integrated, or 'embedded', into IND. This followed the model already in place for many other areas of Home Office research, where research was located more closely to the 'customer', who had far more influence in the commissioning, design and dissemination of research projects. 
This contract between researchers and their customers in IND was formalised through a new procedure for authorising studies, a so-called Project Approval Record, setting out the aims, expected outcome, timeframe and purpose of the research. The form would be sent out for peer review (usually within the Home Office), and then scrutinised by a Project Quality Approval Board. Together with the new embedded structure, the aim was to ensure all research was precisely tailored to IND needs:

There should be nothing happening right now in research without there being an identified need for it. Resource is not so magnanimously given that we can afford to do a pile of research and hope some of it is useful. It's very focused. (Head of Research, Interview, May 2007)

The new system was clearly considered by IRSS to lend their research more credibility, and more generally to legitimise their role within IND. As one senior IND official noted about the new system:

Now they're much more going round to their customers and saying, what is it you want to find out about, can we help you? Or customers are going to them and saying, we need this, can you do a research project? So my sense is that it is being driven by our strategic objectives and our need to fill our knowledge gaps, rather than coming from the research community who are saying this is something it would be interesting to find out. (Interview, May 2007)

So IRSS' structure and relation to policy has undergone a significant shift since 2000. It started as a top-down initiative to enhance the 'evidence base' of Home Office policymaking. This structure encountered problems with legitimacy within IND, which did not consider its research to be useful in informing policy, hence the switch to an embedded structure. Once IRSS became embedded in the IND, however, it appears to have become drawn into conducting research that responded far more directly to organisational needs. As one researcher remarked,

what we've seen evolving is much more ... genuine interest, since we've been through a process of them establishing what evidence they need, and how it's going to be produced, then they're immediately involved and part of that research. (Interview, May 2007)

In the initial phase of IRSS there had been some scope for researchers to define their own agendas and initiate projects. To be sure, they needed to agree an annual business plan with IND, which set out proposed research for the up-coming year. Moreover, any major research project commissioned outside of the business plan needed to be approved by means of a 'submission' to the minister. Business plans were discussed at meetings involving senior policy and operational officials from IND, and often followed up by more detailed meetings with the specific IND customer. However, the definition of projects was an iterative process, and researchers had substantial scope to set the agenda and shape the design and methodology of projects. As one IRSS researcher put it,

We tired hard to ensure their ideas were placed in a broader context - situated in a project that was sound. So we'd broaden it, and plant ideas. So there was interaction. Some projects got dismissed out of hand. Or sometimes, IND would say, yes, we should know about that. So we needed to persuade the customer it was important, and why. (Interview, June 2007) 
This more supply-driven process for defining research changed with the introduction of the new structure in 2004, under which, as we saw, the customer had far more influence. The shift is reflected in the studies that emerged from IRSS. In the initial heyday of IRSS research, the service produced a number of seminal studies which were quite influential beyond the Home Office. This type of broader study effectively ceased from around 2003-2004, replaced by far more narrowly defined reports informing quite specific areas of policy. As one former official put it, 'They're now producing in-house evaluation, management information. So the relationship between the customer and provider is much closer' (Interview, June 2007). This pattern of research supports the earlier point about the shift from projects driven by perceived gaps in knowledge, to a more narrowly instrumental function. As the head of IRSS explained the new emphasis:

\footnotetext{
Essentially it's an evidence process, we need evidence for this, information for that, knowledge here, so that we can make a decision or make a process better, or understand things in a way that helps us to shape policy, so it starts with a conversation that with someone in policy or indeed the operational world, or some other part of business, saying we need some evidence. (Interview, May 2007)
}

Beyond this general trend, though, we should note some significant differences between research areas. The IRSS research agenda, as we saw, was initially divided into areas of immigration, asylum, NASS and integration. Of these areas, research on immigration and its economic and social impact was in many ways the most significant, and indeed pre-dated the establishment of IRSS. In 1999, the Performance and Innovation Unit (PIU) at the Cabinet Office initiated a project on 'Migration: A Social and Economic Analysis', which provided strong evidence that immigration was beneficial to the UK economy. The project was carried out by PIU together with economists from the Home Office, and the Institute for Public Policy Research. It was very much the product of PIU thinking, with the Prime Minister and his advisors increasingly influenced by arguments emerging from the National Skills Task Force and the Department for Trade and Industry about labour and skills shortages. The study had a significant impact both on internal policy debates on immigration, and on the emerging Home Office research agenda. It lent weight to the sorts of arguments about the benefits of immigration that were emerging from the Cabinet Office, giving leverage to those within the Home Office who supported managed migration. And it helped shape the research agenda that emerged after 2000, for the first time bringing economic aspects of migration to the fore, and pointing to gaps in existing research (Interview, May 2007). The ensuing study on the fiscal impact of immigration arguably played an even more prominent role in substantiating the government's new policy. Its estimate that immigrants in the UK had made a net fiscal contribution of $£ 2.5$ billion in 1999-2000 was repeatedly cited in speeches, press releases and parliamentary debates (see, for example, Blunkett 2002).

Research in the area of asylum displayed a somewhat different dynamic. Officials were under pressure to meet a number of narrowly defined performance targets, and there was little interest in research that would not help them in this goal 
(Interview, June 2007). Paradoxically, the lack of interest from IND created a wider margin of manoeuvre for researchers in IRSS working on asylum. Probably the most influential report commissioned by IRSS over this initial phase was on the factors influencing asylum seekers' choice of country (Vaughan and Segrott 2002). The findings were controversial within IND, in many ways contradicting operational received wisdom that legislation on asylum had a major impact on asylum-seekers' choice of country. However, it appears to have had some impact on some of those working on policy. One official working on asylum at the time singled out this study as having a definite influence on his thinking. Shortly after attending a meeting on the report, he drew on the findings when advising on policy:

We needed to understand that policy has an effect, and so having that kind of background was quite important. I can't swear to you that ... we referred directly to the research, but it was there as part of the background. (Interview, May 2007)

Another report on asylum played a clear substantiating function, helping the organisation argue for restricting labour market access to asylum seekers. In 2002 the Treasury and the Department for Work and Pensions were keen to permit asylum-seekers to work, but the Home Office argued this would constitute a pull factor for potential economic migrants. They drew on a report commissioned from researchers at the University of Swansea on the role of social networks in disseminating information on countries or asylum. Although the findings did not directly corroborate the notion that access to employment constituted a pull factor for would-be asylum-seekers, the Home Office was able to add weight to its arguments by pointing to the sound evidence base of its policies. As one former official described this sort of tactic,

There would be two paragraphs on the project. The first would say, we've commissioned research on push/pull factors influencing asylum. The next paragraph would say, we're concerned that the right to work acts as a pull factor. The implication was that this was evidence-based. For IND, the fact that we commissioned research helped them to push their preferences through. It showed a willingness to engage with evidence. (Interview, June 2007)

Interestingly, in 2008 RDS was criticised by the Office of Science Innovation for being insufficiently strategic and forward-thinking. In May 2007, as part of the first stage of the review, the OSI observed that there was a lack of 'horizon-scanning in the Home Office, with too much energy taken up with fire-fighting' (Office of Science and Innovation 2007: 3). This was partly attributed to the embedded structure. While there were thought to be clear benefits to having embedded scientists in the sectors of a department... a weakness of this dispersed approach is the tendency to miss out on longer-term, strategic research needs and to not cover issues that cut across sectoral boundaries (ibid.: 2).

So while the shift to more narrowly defined and instrumental research appears to have enhanced the credibility of IRS within IND, external expectations about the need for more strategic policy research appear not to have been met. As the Head of IRSS observed, 
There is a recognition in the Home Office that we need to get back to being more strategic with our research, and have not all of it focused on what we need to know right now, but to be thinking a little bit ahead what are the issues going to be in the future, doing a bit of horizon scanning. (Interview, May 2007)

The implication is an ongoing tension between prioritising research that is seen as useful by members of the organisation (the embedded model), and responding to external pressures to deliver more strategic thinking. The second, more strategic model appears to a large extent to emanate from outside of the organisation. As in the case of discourse on evidence-based policymaking, it reflected a general concern to improve the quality of decisions and output in the organisation. But the take-up of these ideas within the Home Office is limited. Where Home Office officials do internalise such notions, this is likely to reflect a concern to conform to external expectations about appropriate organisational structures and procedures.

Researchers within IRSS are generally keen to publish their work, in order to maintain their standing within the research community. They are frequently under pressure from the commissioned researchers to carry out research to ensure studies are put out as quickly as possible. Indeed, there have been several cases where researchers working with IRSS have been frustrated at delays of up to 2 years in the publication of research.

Not surprisingly, the view amongst IND and especially the operational staff has been somewhat different. There is a general reluctance to publish findings that may potentially contradict the direction of IND policy, or undermine perceptions about its performance. Even where there is no obvious risk of this occurring, the basic preference seems to be not to publish/publicise work. The view is that there is no advantage to be derived from dissemination, and publication implies an extra layer of procedures: preparing a submission to the minister, editing a report, preparing a press release, and so on. As one former official noted of IND officials, 'If the relationship is one of having a customer or consumer, you produce findings, and they can do what they want with them. There is no added value for them of publishing' (Interview, June 2007).

The divide in opinion reflects divergent view on the function of research. Senior policy people who think more strategically are interested in dissemination as a means of substantiating decisions and, to some extent, legitimising the Home Office through demonstrating its evidence base. Researchers within the organisation are above all interested to demonstrate the expertise of IRSS and their own research credentials. By contrast, the predominant view amongst operational staff and those involved in more detailed policymaking is that dissemination is more trouble than it is worth. Insofar as research is valued at all, its usefulness is in adjusting output to help meet clearly specified targets.

How far does the Home Office case conform to expectations about the culture of knowledge use in the UK bureaucracy? As in the German case, the initial rationale for establishing a research unit was partly legitimising: to conform to expectations about evidence-based research, which were particularly modish in UK government at the time. However, as one might expect in the British case, this agenda was viewed with scepticism and suspicion by officials. And it soon prompted the 
adoption of a so-called 'embedded' structure, under which research independence was subordinated to the needs of the 'customer' users within the organisation. So perhaps unsurprisingly, faced with a similar tension to that experienced in the BAMF between independence/credibility of research and its subordination/direct usefulness to other parts of the organisation, the Home Office opted for the latter model. And this may indeed reflect a different culture of valuing research, one in which it simply is not deemed as important for an organisation to demonstrate its research credentials in order to ensure its decision-making authority.

Paradoxically, though, the research unit has played a substantiating role in policymaking, implying that its research output has had more impact than that of the BAMF. IRSS research has played an important role in underpinning Labour's policy reforms of the early 2000s, in a way that German research simply did not. This seems to be despite the evident lack of a culture of valuing research within the Home Office (or UK public administration more broadly). So the implication is that just because an organisation ascribes to the idea that research should inform policy, it does not necessarily follow that it will make use of research in policymaking; and similarly, just because an organisation appears sceptical about research in general does not mean that it will not make use of research findings where these help realise organisational goals. In short, recognition of the legitimising function of research can be decoupled from actual uptake of research in policymaking.

\subsection{Conclusions}

What does the analysis of research use within these two organisations tell us about cultures of research utilisation? The two cases have interesting parallels. They are both instances of a research unit being introduced in a 'top-down' fashion into an organisation, rather than established in response to perceived organisational needs. In this sense the establishment of both units was motivated by a desire to conform to expectations about 'competence' or 'evidence-based policymaking', rather than to meet 'bottom-up' calls for research to inform policy. In both cases this top-down decision met with scepticism across the organisation about the value of the unit, especially among those involved in more operational aspects of policy.

And yet this tension was resolved in opposite ways in the two administrations. In the German case, concerns about the lack of relevance or usefulness of the research in other parts of the organisation were trumped by the perceived value of the unit as a source of legitimation: the unit's independence was seen as vital for shoring up the epistemic authority of the BAMF. In the UK case, a weaker commitment to the mantra of 'evidence-based policymaking' made it easier to override such considerations. The organisation's need for more applied 'management information' trumped concerns about preserving the scientific credibility of the research unit.

So far, then, the findings appear to be in accordance with our expectations about different cultures of research use in German and UK administration. Yet when we 
look at how findings were (or were not) actually used in policymaking, we are confronted with an apparent anomaly. In the German case, while the administration did appear to attach more importance to the value of research, often this was decoupled from the take-up of research in practice. An almost naïve confidence in the value of research was juxtaposed with a readiness to disregard the 'evidence' in decision-making. The disregard for research did not simply involve discrediting findings or playing down their importance, but quite blatantly ignoring them in deliberation. It suggested that respect for research on the part of policymakers was often largely ceremonial. A rhetorical commitment to the importance of research was coupled with a readiness to debate decisions on an entirely different basis.

In the UK administration, by contrast, far less importance was attached to this form of knowledge base. And yet despite this, officials did quite frequently draw on or commission research to substantiate policy. The most pronounced example of research used to substantiate policy was the research on the economic impact of migration, which was drawn on repeatedly to justify the government's liberalisation of labour migration in the early 2000s. Arguably, this says more about the nature of political contestation over labour migration than it does about the Home Office's organisational culture. For a number of reasons (which there is no space to elaborate here), the Labour government succeeded in pitching the debate in quite technocratic terms, shifting the discussion away from more emotive arguments to a discussion of the economic costs and benefits of labour migration. So the demand for substantiating research emanated more from politicians involved in making the case for labour migration, than from within the Home Office. The German debate on the immigration law, by contrast, drew surprisingly little on research findings. Both political discourse and media coverage relied predominantly on arguments linked to values and interests rather than expert knowledge.

These insights underscore how important it is to distinguish between the different functions knowledge can play, if we are to develop a more nuanced understanding of different cultures of knowledge utilisation. A particular organisation may show high deference for knowledge in the abstract (legitimising knowledge), but rather limited interest in deploying it for the purposes of substantiating or adjusting output. Another may attach little importance to the activity of collecting background knowledge, but consider research very important in substantiating specific claims. And organisations may find different types of knowledge more or less reliable when it comes to adjusting output, preferring more scientific studies, or knowledge acquired through practical experience. Thus the different functions of knowledge may be decoupled from one another.

What are the implications of this for thinking about national 'cultures' of knowledge use? First, the analysis supports the idea that there are distinct German and UK cultures in terms of the value attached to research in the abstract. And this appears to have some influence on the legitimising function of knowledge in the two organisations examined. However, this culture of valuing research does not appear to guarantee that research will be taken up in policymaking. Instead, other factors appear to have more weight in determining how far knowledge plays a substantiating or instrumental function. In the case of substantiating knowledge, what seems to be 
more important is the grounds on which political contestation revolves. If debate revolves around technocratic arguments, then we might indeed expect knowledge to be marshalled to substantiate arguments, even in the absence of a strong culture of valuing expert knowledge within the relevant policymaking organisation. So in effect, the nature of political contestation over a given policy area at a given point of time may over-ride more general characteristics of the organisation, such as the value ascribed to expertise.

In the case of instrumental knowledge, meanwhile, the main factor influencing the use of research to inform policy appears to be the extent to which policymakers are under pressure to deliver short - medium-term results. Where an organisation needs to adjust policy to meet measurable targets, for example reducing asylum applications, then a strong culture of knowledge use may well prompt them to draw on research instrumentally. However, most areas of immigration and asylum policy are highly symbolic, with the implication that there is limited political interest in using knowledge to adjust policy: policymakers secure legitimacy through their rhetoric rather than policy delivery. So regardless of the organisation's culture of valuing knowledge, instrumental knowledge use is likely to be limited in policy areas where legitimation is secured through rhetoric rather than action.

The conclusion, then, is that while national cultures may shape the use of research to legitimise decision makers, other factors appear to be more influential in shaping the use of knowledge for substantiating and instrumental purposes: namely, the nature of political debate (how technocratic it is), and the policy sector (whether legitimation is secured through rhetoric or delivery).

Open Access This chapter is distributed under the terms of the Creative Commons Attribution Noncommercial License, which permits any noncommercial use, distribution, and reproduction in any medium, provided the original author(s) and source are credited.

\section{References}

Beetham, D. (1996). Bureaucracy (2nd ed.). Buckingham: Open University Press.

Blunkett, D. (2002, June 26). Home secretary's speech to the social market foundation. London.

Boswell, C. (2008). The political functions of expert knowledge: Knowledge and legitimation in European Union immigration policy. Journal of European Public Policy, 15(4), 471-488.

Boswell, C. (2009). The political uses of expert knowledge: Immigration policy and social research. Cambridge: Cambridge University Press.

Douglas, M. (1982). In the active voice. London: Routledge and Kegan Paul.

Douglas, M., \& Wildavsky, A. (1982). Risk and culture: An essay on the selection of technological and environmental dangers. Berkeley: University of California Press.

Eckstein, H. (1997). Social science as cultural science, rational choice as metaphysics. In R. Ellis \& M. Thompson (Eds.), Culture matters (pp. 221-244). Boulder: Westview Press.

Geva-May, I. (2002). Cultural theory: The neglected variable in the craft of policy analysis. Journal of Comparative Policy Analysis: Research and Practice, 4(3), 243-265.

Halffmann, W. (2005). Science-policy boundaries: National styles? Science and Public Policy, 32(6), 457-467. 
Hellström, T. (2000). Technoscientific expertise and the significance of policy cultures. Technology in Society, 22, 299-512.

Herbst, S. (2003). Political authority in a mediated age. Theory and Society, 32(4), 481-503.

Hoppe, R. (2002). Cultures of public policy problems. Journal of Comparative Policy Analysis: Research and Practice, 4(3), 305-326.

Jann, W. (2003). State, administration and governance in Germany: Competing traditions and dominant narratives. Public Administration, 81(1), 95-118.

Jasanoff, S. (1995). Product, process, or programme: Three cultures and the regulation of biotechnology. In M. Bauer (Ed.), Resistance to new technology: Nuclear power, information technology and biotechnology (pp. 311-331). Cambridge: Cambridge University Press.

Koenig, K. (2000). The administrative state in Germany. In H. Wollmann \& E. Schroeter (Eds.), Comparing public sector reform in Britain and Germany: Key traditions and trends of modernisation (pp. 47-66). Aldershot: Ashgate.

Lodge, M., \& Hood, C. (2003). Competency and bureaucracy: Diffusion, application and appropriate response? West European Politics, 26(3), 131-152.

Office of Science and Innovation. (2007). Review of science in the home office. London: HM Treasury.

Peters, B. G. (1995). The politics of bureaucracy (4th ed.). White Plains: Longman.

Robinson, V., \& Segrott, J. (2002). Understanding the decision-making of asylum seekers (Home office research study 243). London: Home Office Research, Development and Statistics Directorate.

Thompson, M., \& Wildavsky, A. (1986). A cultural theory of information bias in organisations. Journal of Management Studies, 23(3), 273-286. 